DOI: $10.34220 /$ issn.2222-7962/2021.1/9

УДК 674.812 .06

СВЯЗЬ МЕЖДУ СВОЙСТВАМИ ДРЕВЕСИНЫ И ДЕФОРМАТИВНОСТЬЮ ПРИ РАЗЛИЧНЫХ РЕЖИМАХ НАГРУЖЕНИЯ

\author{
соискатель О.И. Шакирова
}

ФГБОУ ВО «Воронежский государственный лесотехнический университет имени Г.Ф. Морозова», г. Воронеж, Российская Федерация

\begin{abstract}
Модифицирование древесины путем прессования позволяет получить прочный материал из низкокачественных пород древесины. Связь между строением натуральной и прессованной древесины и деформативностью исследована в работах Б.И. Огаркова, П.П. Эриньша, В.А. Шамаева, Г.К. Гаврилова. Между тем в настоящее время деформированию на практике подвергают древесину в пластифицированном состоянии, строение и свойства которой отличны от строения натуральной древесины. В настоящей работе предпринята попытка установить взаимосвязь между строением натуральной и пластифицированной древесины и ее основными деформативными показателями (жесткость, модуль упругости, коэффициент Пуассона и т.д.). В результате экспериментов установлено, что по результатам обработки эмпирических диаграмм «деформация - напряжение» установлен трехфазный характер деформирования древесины березы натуральной и пластифицированной маслом ЖТК (жидкость термокаталитического крекинга) с расчетом показателей жесткости; получены зависимости коэффициента Пуансона при переменных влажности и температуре в процессе прессования для постоянной и переменной скорости нагружения; изучен гистерезис в древесине при растяжении и сжатии для натуральной и пластифицированной древесины.
\end{abstract}

Ключевые слова: модифицированная древесина, пропитка, прессование, реология, масло ЖТК (жидкость термокаталитического крекинга)

\title{
RELATIONSHIP BETWEEN WOOD PROPERTIES AND DEFORMATIVITY UNDER DIFFERENT LOADING MODES
}

\section{O.I. Shakirova}

FSBEI HE "Voronezh State University of Forestry and Technologies named after G.F. Morozov", Voronezh, Russian Federation

Modification of wood by pressing makes it possible to obtain a durable material from low-quality wood species. The relationship between the structure of natural and pressed wood and deformability was investigated in the works of B.I. Ogarkov, P.P. Erinsh, V.A. Shamaev, G.K. Gavrilov. Meanwhile, at present wood is subjected to deformation in a plasticized state, the structure and properties of which are different from the structure of natural wood. In this work, an attempt to establish the relationship between the structure of natural and plasticized wood and its main, deformative indicators (stiffness, modulus of elasticity, Poisson's ratio, etc.) has been made . As a result of the experiments, it was found that (according to the results of processing empirical diagrams "deformation - stress") a three-phase nature of deformation of natural birch wood and plasticized with TCL (thermocatalytic cracking liquid) oil was established with the calculation of stiffness indicators; the dependences of the Punch ratio at variable humidity and temperature during the pressing process for constant and variable loading rates were obtained. Hysteresis in wood under tension and compression for natural and plasticized wood has been studied.

Keywords: modified wood, impregnation, pressing, rheology, ZHTK oil (thermocatalytic cracking liquid) 


\section{Деревопереработка. Химические технологии}

\section{Введение}

Модифицирование древесины путем прессования позволяет получить прочный материал из низкокачественных пород древесины $[1,2,6,9]$.

Прессование древесины - одно из наиболее перспективных направлений улучшения ее физикомеханических свойств. Материал, получаемый в результате уплотнения древесины, обладает более высокими прочностными свойствами по сравнению с исходной (натуральной) древесиной. Поэтому его можно использовать в качестве конструкционного материала, способного выступать в качестве заменителя черных и цветных металлов, текстолита и многих видов пластмасс.

Как известно, натуральная древесина является конструкционным материалом сравнительно невысокой прочности. Ее прочность можно повысить, наполняя пустоты, составляющие $30 \ldots 80 \%$ eе объема, армирующими наполнителями, в основном полимерами и металлами, а также древесным веществом путем прессования.

Связь между строением натуральной и прессованной древесины и деформативностью исследована в работах Б.И. Огаркова, П.П. Эриньша, В.А. Шамаева, Г.К. Гаврилова. Между тем в настоящее время деформированию на практике подвергают древесину в пластифицированном состоянии, строение и свойства которой отличны от строения натуральной древесины $[4,5,8,11]$. В настоящей работе предпринята попытка установить взаимосвязь между строением натуральной и пластифицированной древесины и ее основными деформативными показателями (жесткость, модуль упругости, коэффициент Пуассона и т.д.).

Пластифицированная древесина содержала 10 \% масла ЖТК (жидкость термокаталитического крекинга) от массы абсолютно сухой древесины. Именно такое содержание масла имеет место при получении шпал $[3,10,12]$. Прессованная древесина была получена по способу П.Н. Хухрянского и имела следующие показатели: плотность $1000 \pm 50$ кг $/ \mathrm{M}^{3}$, влажность 6-7 \%, порода - береза (Betula verrucosa $\mathrm{L}$.)

В процессе прессования с помощью реологии устанавливаются оптимальные параметры воздействия на материал: величина усилий, темпера- тура, влажность и др., от которых будет зависеть качество готовой продукции [7].

Рассмотренные работы по реологии натуральной и прессованной древесины относятся к процессам, исследованным от нескольких секунд до нескольких часов, т.е. от $10^{2}$ до $10^{8}$ с при среднем времени $10^{5} \mathrm{c}$ (28 часов).

Целью настоящей работы было установление корреляционных зависимостей реологического поведения древесины в условиях нагружения и разгрузки при поперечных параметрах прессования (влажность, температура, пластификатор). При этом учитывалось, что основным фактором, определяющим строение древесины, было состояние пластичности, т. е. содержание модификатора.

\section{Материалы и методы}

Перед проведением эксперимента подготавливается оборудование и образцы размерами $60 \times 120 \times 300$ мм, исходным материалом была древесина березы (Betula verrucosa L). Плотность сырья при влажности $12 \%$ составляла $640 \pm 20$ кг $/ \mathrm{M}^{3}$. Образец замеряется во всех трех направлениях и взвешивается. Нагружение производится в направлении поперек волокон по размеру 120 мм. При сжатии вдвое наблюдается процесс релаксации напряжений. Для этого производится нагружение, включается секундомер и производится запись спада упругого сопротивления во времени по общему графику. Работа носит вспомогательный характер и имеет основную направленность на оценку масштабного фактора.

При работе на испытательной машине ZDMU-30t (рис. 1) наблюдению подлежит процесс релаксации напряжений.

Спад упругого сопротивления отмечается по секундомеру и силоизмерителю при постоянной деформации. Замеры заготовок производят штангенциркулем, затем образцы взвешивают и вместе с пресс-формой доводят до нужной температуры. Взвешенный и замеренный образец помещают в пресс-форму, устанавливают на подвижную часть пресса машины и производят нагружение. Включают секундомер и выключают нагружатель. Спад упругого сопротивления отмечается через $30 \mathrm{c}, 1,3$, 5 мин, а при возможности через 30 мин, 1,3 и 5 часов и далее до изменения деформации или пол-

Лесотехнический журнал 1/2021 
ного падения упругого сопротивления. Из полученной информации вычитается уровень фона, характеризующий утечку масла в плунжерных парах. Эксперимент прекращается при изменении деформации более чем на 0,5 мм (до 1,5\% от заданной степени прессования). В общем случае наблюдению подлежит спад напряжений в образце, запрессованном вдвое, что соответствует наиболее типичному случаю прессования древесины. Здесь $\varepsilon=0,5$, или $50 \%$.

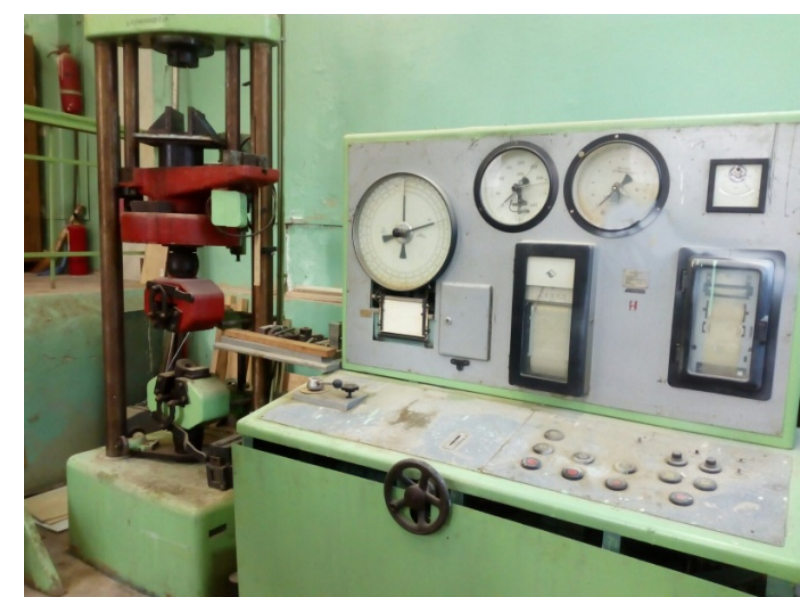

Рис.1. Испытательная машина ZDMU-30t на сжатие и разрыв

Источник: результат получен автором

Результаты и обсуждение

По результатам обработки эмпирических диаграмм «нагрузка - деформация» при прессовании древесины поперек волокон были определены показатели жесткости пластифицированной древесины для первой, второй и третьей фаз деформирования. Для первой фазы жесткость определялась в зоне деформации $\varepsilon 1=0,05 \ldots 0,1$, для второй и третьей фаз соответственно $\varepsilon 2=0,15 \ldots 0,35$; $\varepsilon 3=0,5 \ldots 0,55$. Значения жесткости приведены в табл. 1.

Здесь жесткость древесины выступает как модуль упругости и рассчитывается аналогично. Анализ табл. 1 показывает, что сопротивление сосудов и клеток сжатия (вторая фаза) практически не изменилось в результате пропитки древесины антисептиком, С повышением влажности жесткость значительно снижается; так, при увеличении влажности в 5 раз показатель жесткости уменьшается в 2 раза. Различие деформативных показателей первой и третьей фаз весьма значительно - в 2-2,5 раза, причем максимальное различие приходится на древесину меньшей влажности.

Таблица 1

Показатели жесткости натуральной (А) и пластифицированной (B) древесины при сжатии в радиальном направлении

\begin{tabular}{|l|l|l|l|l|l|l|}
\hline \multirow{2}{*}{\begin{tabular}{l} 
Влаж \\
\multirow{2}{*}{$\begin{array}{l}\text { ность } \\
\%\end{array}$}
\end{tabular}} & \multicolumn{4}{|l|}{ Жесткость древесины, МПа в фазе сжатия } \\
\cline { 2 - 7 } & 1-я фаза & \multicolumn{2}{|l|}{ 2-я фаза } & \multicolumn{2}{|l}{ 3-я фаза } \\
\hline 5 & 327 & 66,60 & 21,70 & 22,20 & 138 & 51,25 \\
\hline 10 & 200 & 65,40 & 19,60 & 16,35 & 121 & 47,83 \\
\hline 15 & 180 & 62,75 & 16,35 & 16,35 & 121 & 47,83 \\
\hline 20 & 125 & 58,00 & 14,60 & 9,80 & 100 & 41,10 \\
\hline$\underline{25}$ & 121 & 40,90 & 10,90 & 9,80 & 100 & 40,90 \\
\hline
\end{tabular}

Источник: результат получен автором

По мере увеличения влажности как для натуральной, так и для пластифицированной древесины различие жесткости первой и третьей фаз невелико. Это свидетельствует в пользу разрабатываемой теории о двух составляющих процесса деформирования и его бинарном механизме. С увеличением влажности древесины снижается значение фактора пропитки. Так, если наполнение маслом снижает жесткость сухой древесины почти в 5 раз, то для влажной - чуть более чем в 2 раза. Снижение различия жесткости древесины на первой и третьей фазах сжатия при повышении влажности древесины подтверждает, что кроме сосудов деформативность определяют и клетки либриформа. Кроме того, меняют собственную пластичность стенки клеток, что позволяет с меньшими затратами повышать плотность их упаковки. Из табл. 1 видно, что податливость древесины в стадии смятия сосудов на порядок больше соответствующих значений первой и третьей фаз.

Помимо показателя жесткости процесс деформирования характеризуется наличием коэффициента поперечной деформации, являющегося функцией степени прессования. Кроме того, на величину поперечной деформации влияет и наличие пластификатора (табл. 2). Данные в табл. 2 приведены для натуральной древесины березы плотностью 615 кг $/ \mathrm{M}^{3}$ и пластифицированной плотностью

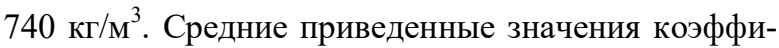




\section{Деревопереработка. Химические технологии}

циента поперечного деформирования сведены в табл. 3. Коэффициент $\mu \mathrm{t} 2 \approx \mu 0 \mathrm{t}$ рассчитывается по формуле

$$
\mu=\mathrm{k} \mu \frac{\Delta b / b}{\Delta h / h},
$$

где $b$ и $h$ - соответственно ширина и высота образца, a $\Delta \mathrm{b}$ и $\Delta \mathrm{h}$ - их изменение после сжатия;

$\mathrm{k} \mu$ - коэффициент, учитывающий неравномерное изменение боковых размеров по высоте образца, другими словами, бочкообразную форму образца после сжатия за счет сил трения между поверхностями образца и сжимающих плит, $\mathrm{k} \mu=0,785$.

Как видно из табл. 2 и 3, при малых деформациях поперечное деформирование не изменяется вследствие пропитки древесины маслом. Различие становится заметным при деформации, превышающей 30 \%, т. е. после смятия основной массы оставшихся свободными после пропитки карбамидом сосудов. Это подтверждает чисто механический характер начала и развития поперечного деформирования.

С другой стороны, можно отметить, что зависимость поперечного деформирования от степени сжатия в результате пластификации претерпевает некоторые качественные изменения. В то время как поперечные размеры натуральной древесины при прессовании возрастают по весьма пологой кривой, почти линейно, то увеличение поперечных размеров пластифицированной древесины происходит с возрастающей кривизной к оси поперечного деформирования (рис. 2)
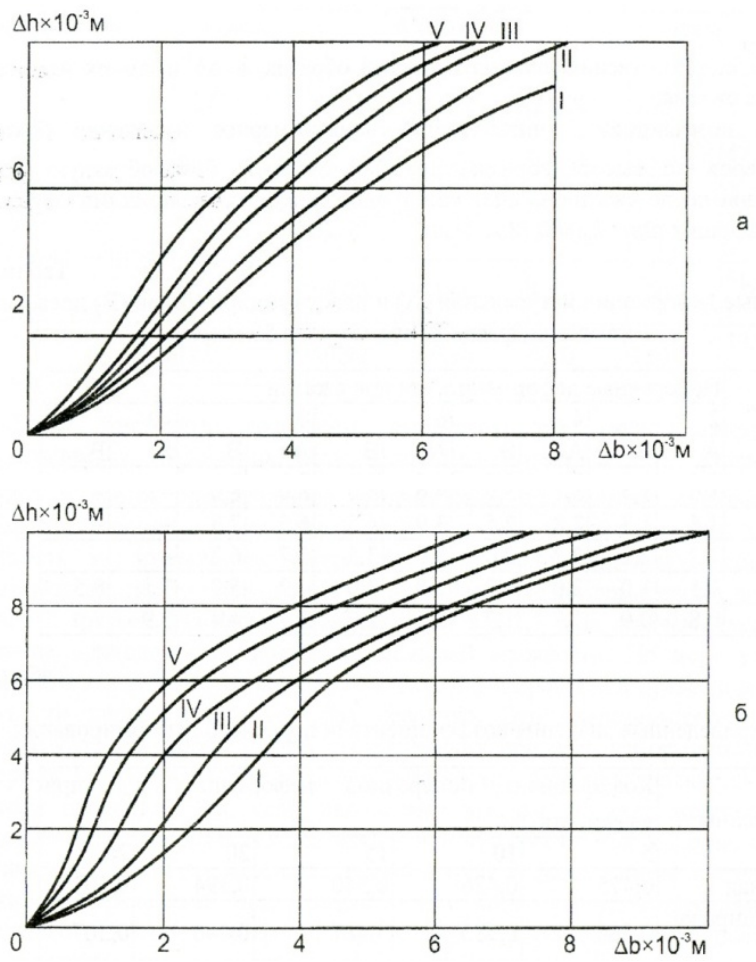

Рис. 2. Максимальные поперечные деформации натуральной (а) и пластифицированной (б) древесины влажностью: $1-5 \% ; 2-10 \% ; 3-15 \%$; $4-20 \% ; 5-25 \%$

Источник: результат получен автором

Поперечные деформации натуральной (А) и пластифицированной (В) древесины (высота образца 20 мм, ширина 30 мм)

\begin{tabular}{|l|c|c|c|c|c|c|c|c|c|c|}
\hline \multirow{3}{*}{ Влажность, \% } & \multicolumn{8}{|c|}{ Поперечные деформации, мм при сжатии } \\
\cline { 2 - 14 } & \multicolumn{2}{|c|}{2} & \multicolumn{2}{|c|}{4} & \multicolumn{2}{|c|}{6} & \multicolumn{2}{|c|}{8} & \multicolumn{2}{|c|}{10} \\
\cline { 2 - 14 } & $\mathrm{A}$ & $\mathrm{B}$ & $\mathrm{A}$ & $\mathrm{B}$ & $\mathrm{A}$ & $\mathrm{B}$ & $\mathrm{A}$ & $\mathrm{B}$ & $\mathrm{A}$ & $\mathrm{B}$ \\
\hline 5 & 1,6 & 1,5 & 3,1 & 3,0 & 4,6 & 5,0 & 8,0 & 8,0 & - & - \\
\hline 10 & 1,4 & 1,3 & 2,8 & 2,5 & 3,9 & 4,5 & 6,5 & 7,3 & - & - \\
\hline 15 & 1,2 & 2,2 & 2,2 & 2,0 & 3,5 & 3,5 & 5,7 & 6,2 & - & - \\
\hline 20 & 1,1 & 1,0 & 2,0 & 1,8 & 2,8 & 3,0 & 4,2 & 5,2 & 7,1 & 8,5 \\
\hline 25 & 0,8 & 0,9 & 1,7 & 1,7 & 2,5 & 2,7 & 3,7 & 4,4 & 5,9 & 7,0 \\
\hline
\end{tabular}


Таблица 3

Средние приведенные значения коэффициента поперечного деформирования

\begin{tabular}{|l|c|c|c|c|c|}
\hline \multirow{2}{*}{ Вид древесины } & \multicolumn{4}{|l|}{ Коэффициент поперечной деформации $\mu \mathrm{rt}$ при } \\
& влажности, \% \\
\cline { 2 - 6 } & 5 & 10 & 15 & 20 & 25 \\
\hline Натуральная & 0,475 & 0,426 & 0,340 & 0,394 & 0,303 \\
\hline Пластифицированная & 0,580 & 0,533 & 0,487 & 0,446 & 0,367 \\
\hline
\end{tabular}

Источник: результат получен автором

Вследствие влияния сцепления и трения поверхностей форма выпуклости поперечного увеличения ширины образца близка к части окружности, т.е. коэффициент пересчета может быть принят равным $\frac{\pi}{4}$. Тогда для натуральной древесины $\mu=0,420$, для пластифицированной $\mu=0,497$. Максимальное различие величин поперечного деформирования достигается при больших степенях прессования.

Поперечное деформирование при сжатии образца возрастает с уменьшением влажности и в исследованном диапазоне достигает максимума при $W=5 \pm 1 \%$. Здесь его величина близка к соответствующей высокоэластическим материалам, а изменение объёма минимально. По мере повышения влажности поперечное деформирование снижается, приближаясь к величинам, характерным для металлов. Прессование древесины может проводиться либо с постоянной скоростью нагружения, либо с постоянной скоростью деформирования в зависимости от применяемой прессовой аппаратуры.

В процессе эксперимента было рассмотрено прессование древесины березы при постоянной скорости деформирования, равной 4 мм/мин на образцах $20 \times 20 \times 30$ мм при сжатии в радиальном или тангенциальном направлении на 50 \% (табл. 4).

Процесс нарастания напряжений во времени при постоянной скорости деформирования является типичным для прессования, соответствует известной диаграмме «напряжение-деформация древесины» и также имеет три участка. Средний участок в основном определяется процессом смятия сосудов древесины, а также полостей волокон либриформа, волокнистых трахеид и других пустот. При приближенном представлении этой фазы отрезком прямой можно заметить, что угол наклона ее к оси абсцисс (время) возрастает по мере уменьшения влажности древесины.

Нарастание напряжений в древесине при постоянной скорости деформирования

\begin{tabular}{|l|l|l|l|l|l|}
\hline \multirow{2}{*}{$\begin{array}{l}\text { Влаж- } \\
\text { ность } \\
\text { древе- } \\
\text { сины, } \%\end{array}$} & \multicolumn{5}{|l|}{ Напряжение МПа через промежуток, с } \\
\cline { 2 - 6 } & 30 & 60 & 90 & 120 & 150 \\
\hline 5 & 11,30 & 14,18 & 15,90 & 19,15 & 25,30 \\
\hline 10 & 9,87 & 12,00 & 13,90 & 17,20 & 23,60 \\
\hline $\begin{array}{l}10 \text { пла- } \\
\text { стифи- } \\
\text { циро- } \\
\text { ванная }\end{array}$ & 3,94 & 4,75 & 7,65 & 12,80 & 19,20 \\
\hline 15 & 8,001 & 9,75 & 11,72 & 13,15 & 22,00 \\
\hline 20 & 7,15 & 8,35 & 9,50 & 11,90 & 17,00 \\
\hline 25 & 5,63 & 6,66 & 8,17 & 10,65 & - \\
\hline
\end{tabular}

Источник: результат получен автором

В первом приближении нарастание напряжения $\sigma \tau$ во времени $\tau$ в зависимости от влажности $W$ можно рассчитать по формуле

$$
\sigma \tau=2,7(46-w)+\left(1,2-\frac{w}{30}\right)(\tau-30) .
$$

По времени деформирование древесины по второй фазе начинается через 5-6 с после приложения нагрузки и завершается примерно через $30 \mathrm{c}$.

Нагружение пластифицированной древесины в начальной стадии вызывает менее напряженное состояние. Так, при влажности пластифицированной древесины $10 \%$ напряжения в ней ниже, чем для натуральной древесины влажностью 20-25 \%, особенно в начальный период деформирования. При больших степенях прессования пластифицирующий эффект снижается за счет фактора плотности наполненной древесины. Однако и при больших деформациях пластифицированная древесина не разрушается за счет выдавливания и скола в боках, что характерно для натуральной древесины. 


\section{Деревопереработка. Химические технологии}

Составляющие деформации анализировали во времени по процессу восстановления размеров после снятия нагрузки. Деформации, исчезающие со скоростью снятия нагрузки, т.е. практически мгновенно, являются упругими. В ряде случаев мгновенное разгружение было неосуществимо и разгрузка проводилась со скоростью 130 мм/мин, что при наличии остаточных и запаздывающих деформаций занимало 5 с. Последующие замеры проводились через каждые $60 \mathrm{c}$, так что на временной шкале продолжительность разгрузки представляется незначительной (табл. 5).

Таблица 5

Восстановление размеров образца после снятия нагрузки при начальной высоте 20 мм, степени сжатия 0,5

\begin{tabular}{|l|l|l|l|l|l|}
\hline \multirow{2}{*}{} & \multicolumn{5}{|l|}{ Размеры образца, мм через с } \\
\cline { 2 - 6 } & 60 & 120 & 180 & 240 & 600 \\
\hline 5 & 13,1 & 13,3 & 13,3 & 13,3 & 13,4 \\
\hline 10 & 13,5 & 13,6 & - & - & 13,7 \\
\hline $\begin{array}{l}10 \text { пласти- } \\
\text { фициро- } \\
\text { ванная }\end{array}$ & 16,1 & 18,5 & 19,2 & 19,6 & 20,0 \\
\hline 15 & 14,1 & 14,2 & 14,3 & 14,3 & 14,5 \\
\hline 20 & 14,8 & 15,1 & - & - & 15,3 \\
\hline $\begin{array}{l}20 \text { пласти- } \\
\text { фициро- } \\
\text { ванная }\end{array}$ & 18,3 & 19,7 & 19,8 & 20,0 & - \\
\hline 25 & 15,2 & 15,5 & 15,9 & 16,1 & 16,3 \\
\hline
\end{tabular}

Источник: результат получен автором

Анализ данных табл. 5 показывает, что все виды деформаций зависят от влажности. Чем выше влажность, тем полнее восстанавливаются размеры и форма образца, деформированного сжатием. Образцы с большей влажностью имели большую продолжительность периода восстановления. Нарастание времени завершения соответствующей распрессовки происходило также криволинейно.

Так, если древесина с влажностью порядка $10 \%$ стабилизировалась за 1 мин, с влажностью $20 \%$ - за 2 мин, то с влажностью $25 \%$ - уже за 5 мин.

Пропитка древесины маслом резко меняет картину восстановления размеров и формы образца, деформированного сжатием. Так, при влажности $10 \%$ пластифицированная древесина стабили- зировалась около 10 мин, при этом высокоэластические деформации, включающие здесь квазиупругую и часть запаздывающих, составляли до $85 \%$. Пластифицированная древесина влажностью $20 \%$ за 1-5 мин восстанавливала свои размеры полностью, что свидетельствует о высокоэластическом состоянии материала. Прессование с постоянной скоростью нагружения проводилось в тех же условиях, что и для постоянной скорости деформирования при средней плотности древесины $610 \mathrm{\kappa г} / \mathrm{m}^{3}$. Результаты приведены в табл. 6.

Таблица 6

Прессование древесины при постоянной скорости нагружения $\mathrm{V} \sigma=27,35 \mathrm{KПа} / \mathrm{c}$

\begin{tabular}{|c|c|c|c|c|}
\hline $\begin{array}{l}\text { Влаж- } \\
\text { ность } \\
\text { древе- } \\
\text { сины, } \\
\%\end{array}$ & $\begin{array}{l}\text { Начало } \\
\text { второй } \\
\text { фазы } \\
\text { форми- } \\
\text { рова- } \\
\text { ния, \% }\end{array}$ & $\begin{array}{l}\text { Напря } \\
\text { жение } \\
\text { за- } \\
\text { прес- } \\
\text { совки, } \\
\text { МПа }\end{array}$ & $\begin{array}{l}\text { Оста- } \\
\text { точная } \\
\text { дефор- } \\
\text { фор- } \\
\text { мация, } \\
\text { от є, \% }\end{array}$ & $\begin{array}{l}\text { Время } \\
\text { стаби- } \\
\text { лизации } \\
\text { разме- } \\
\text { ров, с }\end{array}$ \\
\hline 5,3 & 6,0 & 28,6 & 29,6 & 330 \\
\hline 7,1 & 6,0 & 26,0 & 33,8 & 360 \\
\hline 13,0 & 6,5 & 19,5 & 38,1 & 360 \\
\hline 18,0 & 7,0 & 17,2 & 46,5 & 360 \\
\hline 21,2 & 7,0 & 16,4 & 52,8 & 390 \\
\hline
\end{tabular}

Источник: результат получен автором

Условно-упругие деформации в древесине с повышением влажности возрастают, одновременно возрастают и остаточные. При этом чем больше влажность, тем менее задержанным является процесс взаимного превращения деформаций. Однако время релаксации деформаций для всех случаев оказалось величиной одного порядка, в среднем составляя около 360 с. Во время восстановления части размеров образца за счет снятия запаздывающих деформаций у образцов с влажностью $18-21 \%$ за 120 с переходный процесс протекает на $82 \%$, а теряется около $4 \%$ общей деформации. Это означает, что при прессовании с малой скоростью при равномерном наращивании усилия за 15-20 мин успевают пройти основные процессы перестройки структуры древесины. Заметное деформирование при сравнительно малом увеличении нагрузки начинается при $\varepsilon=6-7 \%$, эта величина мало зависит от влажности. Для оценки влияния

Лесотехнический журнал 1/2021 
способа нагружения сравнивались процессы прессования с постоянной скоростью нагружения и с постоянной скоростью деформирования (табл. 7). Последний способ типичен для существующего оборудования и обеспечивается большим запасом мощности гидравлических прессов. При сжатии с постоянной скоростью нагружения и с постоянной скоростью деформирования величины механических напряжений практически одинаковы для обоих режимов прессования.

Таблица 7

Напряжение в древесине при различных условиях сжатия

\begin{tabular}{|c|c|c|c|c|c|c|}
\hline \multirow{2}{*}{$\begin{array}{l}\text { Условия } \\
\text { сжатия: } \\
\text { постоян- } \\
\text { ная ско- } \\
\text { рость }\end{array}$} & \multirow{2}{*}{$\begin{array}{l}\text { Время } \\
\text { прес- } \\
\text { сова- } \\
\text { ния, } \\
\text { с }\end{array}$} & \multicolumn{5}{|c|}{$\begin{array}{l}\text { Напряжения в древесине, МПа } \\
\text { при деформации сжатия }\end{array}$} \\
\hline & & 0,1 & 0,2 & 0,3 & 0,4 & 0,5 \\
\hline $\begin{array}{l}\text { нагруже- } \\
\text { ния } \\
\text { Vб = } 113 \\
\text { КПа/с }\end{array}$ & 200 & 10,2 & 11,8 & 13,6 & 16,8 & 23,8 \\
\hline $\begin{array}{l}\text { Дефор- } \\
\text { мирова- } \\
\text { ния } \\
\mathrm{V \varepsilon}=4,0 \\
\text { мм/с }\end{array}$ & 150 & 10,2 & 12,2 & 14,5 & 17,5 & 22,9 \\
\hline
\end{tabular}

Источник: результат получен автором

При деформировании образцов, пластифицированных маслом, напряжения сжатия в 2,53,0 раза меньше, чем у образцов из натуральной древесины. В конце процесса прессования различия сглаживаются и не превышают $12 \%$.

На процесс нагружения как натуральной, так и пластифицированной древесины практически не оказывает влияния увеличение скорости нагружения в 4 раза. Соответствующие кривые в пределах разброса соответственных показателей отдельных образцов совладают. Заметное влияние скорости нагружения проявляется при разгрузке спрессованных вдвое образцов (табл. 8).

Увеличение скорости нагружения при прессовании натуральной древесины снижает величину остаточной деформации во всем диапазоне влажностей.
Для пластифицированной древесины остаточные деформации зависят от времени нагружения только при малых влажностях. В то же время при влажности 25 \% после снятия нагрузки при комнатной температуре за 5-6 мин происходит полное восстановление размеров образца.

Таблица 8

Остаточные деформации в древесине,

запрессованной с различной скоростью

\begin{tabular}{|c|c|c|c|c|}
\hline \multirow{3}{*}{$\begin{array}{l}\text { Влаж } \\
\text { ность, } \\
\%\end{array}$} & \multicolumn{4}{|c|}{$\begin{array}{l}\text { Остаточные деформации, \% при ско- } \\
\text { рости нагружения }\end{array}$} \\
\hline & \multicolumn{2}{|c|}{ 2,7 КПа/с } & \multicolumn{2}{|c|}{$27 \mathrm{K \Pi а} / \mathrm{c}$} \\
\hline & $\begin{array}{l}\text { нату- } \\
\text { ту- } \\
\text { раль } \\
\text { ной }\end{array}$ & $\begin{array}{l}\text { пласти- } \\
\text { фициро- } \\
\text { ванной }\end{array}$ & $\begin{array}{l}\text { нату- } \\
\text { раль- } \\
\text { ной }\end{array}$ & $\begin{array}{l}\text { пласти- } \\
\text { фициро- } \\
\text { ванной }\end{array}$ \\
\hline 5 & 42 & 25 & 34 & 21 \\
\hline 15 & 35 & 15 & 28 & 15 \\
\hline 25 & 26 & 0 & 22 & 0 \\
\hline
\end{tabular}

Источник: результат получен автором

При сжатии древесины поперек волокон помимо собственно процесса прессования протекает ряд других процессов, связанных с поперечным деформированием, контактными взаимодействиями и внутренним трением. При растяжении побочные процессы отсутствуют и появляется возможность оценить величину собственно процесса прессования путем последовательного сжатия и растяжения одних и тех же образцов. Значение деформаций при сжатии и растяжении, а также соответствующие значения при плавной разгрузке (гистерезис) приведены в табл. 9 для образцов высотой 20 мм, влажностью $20 \%$ и температуре $20{ }^{\circ} \mathrm{C}$.

Таблица 9

Общие деформации и гистерезис в древесине при растяжении и сжатии

\begin{tabular}{|l|l|l|l|l|l|l|l|}
\hline \multirow{2}{*}{$\begin{array}{l}\text { Вид } \\
\text { испы- } \\
\text { тания }\end{array}$} & \multicolumn{6}{|c|}{ Деформация, мкм, при напряжений, МПа } \\
\cline { 2 - 8 } & 0 & 0,25 & 0,50 & 0,75 & 1,00 & 1,25 & 1,50 \\
\hline $\begin{array}{l}\text { Растя- } \\
\text { жение }\end{array}$ & - & 1 & 3 & 10 & 21 & 36 & 43 \\
\hline Сжатие & - & 4 & 13 & 33 & 70 & 140 & 201 \\
\hline $\begin{array}{l}\text { Гисте- } \\
\text { резис } \\
\text { растя- } \\
\text { жения }\end{array}$ & 5 & 5 & 17 & - & 28 & 42 & - \\
\hline $\begin{array}{l}\text { Гисте- } \\
\text { резис } \\
\text { сжатия }\end{array}$ & 4 & 8 & 22 & - & & 180 & - \\
\hline
\end{tabular}

Источник: результат получен автором 


\section{Деревопереработка. Химические технологии}

Как видно из табл. 9, деформации сжатия более чем в 3 раза превышают деформации растяжения. Это означает, что даже при сжатии древесины в наиболее упругой области, при минимальных нагрузках, деформации прессования составляют более $2 / 3$ от всех деформаций древесины. Следовательно, процесс прессования протекает практически на всем протяжении сжатия древесины и является определяющим.

Таким образом, оценивая связь анатомического строения древесины с ее деформативностью, можно констатировать, что на первой фазе сжатия при напряжениях, меньших условного предела прочности, преобладает условно упругая деформация. Энергия прессования передается упругим элементам, переходящим в напряженное состояние. Лигноуглеводный комплекс в силу жесткого ограничения целлюлозным каркасом играет здесь роль демпфера, сглаживающего деформативные процессы. Он же затрудняет поперечное деформирование и задерживает развитие деформаций в направлении прессования. При этом деформации упругого типа развиваются не мгновенно. Только поверхностные слои деформируются со скоростью приложения нагрузки, последующие - со все большим запаздыванием. При этом возникают местные перегрузки контактного типа, приводящие к досрочному переходу древесины поверхностных слоев во вторую фазу деформирования.

Во второй фазе сжатия развивается интенсивное перемещение элементов структуры древесины - клеток и сосудов. Поскольку все элементы разного диаметра и разной толщины стенок, процесс смятия полостей происходит весьма неравномерно. На каждой полосе перемещения общая деформация постоянна, в то время как устойчивость составляющих звеньев бессистемна. Звенья теряют устойчивость в случайном порядке, вследствие чего перемещение внутренних слоев прессуемой древесины далеко не параллельно. При наблюдении за процессом прессования отмечаются многочисленные флуктуации, отдельные элементы изменяют свое положение значительно интенсивнее сближе- ния прессующих плоскостей и весьма произвольно. Преобладающее сочетание тонких и толстостенных труб, как наиболее устойчивое образование, врезается в зону тонкостенных крупных сосудов, вызывая нарушение горизонтальных связей, что приводит к проявлениям разрушения. По мере прессования в средней фазе сминается все больше трубчатых элементов, последними сплющиваются наиболее жесткие элементы малого диаметра (типа либриформа). Здесь древесина деформируется как конструкция, где податливость трубчатых образований дополняется демпфирующими особенностями квазижидких инкрустов. Вследствие этого слои, более близкие к нагружателю, во второй фазе сжатия не только раньше воспринимают нагрузку и больше деформируются, но и больше деструктируют. Развивающиеся в поверхностных слоях быстрые релаксационные процессы, включающие накапливающиеся микроразрушения, берут часть деформаций на себя. Это приводит к разнодеформированности контактных и внутренних слоев прессуемой древесины. Если процесс прессования прекратить на второй фазе, то различие плотностей по сечению образца будет максимальным.

В третьей фазе происходит быстрое выравнивание плотности по сечению и заполняются последние пустоты. По мере прессования влияние структурных элементов снижается.

\section{Выводы}

1. По результатам обработки эмпирических диаграмм «деформация - напряжение» установлен трехфазный характер деформирования древесины березы натуральной и пластифицированной маслом ЖТК (жидкость термокаталитического крекинга) с расчетом показателей жесткости (уравнение 2).

2. Получены зависимости коэффициента Пуансона при переменных влажности и температуре в процессе прессования для постоянной и переменной скорости нагружения (уравнение 1).

3. Изучен гистерезис в древесине при растяжении и сжатии для натуральной и пластифицированной древесины. 


\section{Библиографический список}

1. Шамаев, В. А. Модифицирование древесины : монография / В. А. Шамаев, Н. С. Никулина, И. Н. Медведев. - Москва : ФЛИНТА : Наука, 2013. - 448 с.

2. Effect of combined compression and thermal modification on mechanical performance of aspen and birch wood / V. Möttönen, Y. Bütün, H. Heräjärvi [et al.] // Pro Ligno. - 2015. - Vol. 11. - No. 4. - P. 310-317.

3. Губанова, Н. В. Моделирование процесса пропитки древесины жидкостью / Н. В. Губанова // Вестник Московского государственного университета леса - Лесной вестник. - 2013 - № 3 (95). - С. 134-138.

4. Cox, P. E.Wood hardening procedures. Pat. USA WO2006121352A1, PCTNZ 2006/000105. 2006. 11 p.

5. Papadopoulos, A. N. Vapour Sorption Studies of Belmadur Wood / A. N. Papadopoulos, G. I. Mantanis // Advances in Forestry Letter (AFL). - 2012. - Vol. 1. - Issue 1. - P. 1-6.

6. Poncsak, S. Improvement of the heat treatment of jack pine (Pinus banksiana) using thermowood technology / S. Poncsak, D. Kocaefe, R. Younsi // Holz als Rohund Werkstoff. - 2011. - Vol. 69. - № 2. - P. 281-286.

7. Тюленева, Е. М. Уточнение реологической модели древесины / Е. М. Тюленева // Хвойные бореальной зоны. - 2008. - XXV. - № 1-2. - С. 179-183.

8. Пропитка древесины жидкостями под давлением / В. А. Шамаев, О. А. Куницкая, И. В. Григорьев [и др.] // Системы. Методы. Технологии. - 2018. - № 4 (40). - С. 152-156. - DOI 10.18324/2077-5415-2018-4$152-156$.

9. Durability of Modified Wood - Laboratory vs Field Performance. Westin Mats, Technical Research Institute of Sweden, Boras, Sweden, 2010, 142.

10. Official site of Accoya company. - URL: https://www.accoya.com/why-accoya/benefits/.

11. Official site of Kebony company. - URL: http://kebony.com/en/products/.

12. Патент РФ № 2185958 Шамаев В.А. Способ изготовления деревянной шпалы / В. А. Шамаев, А. А. Томин, А. И. Сидельников. Заявл. 11.08.2001, опубл. 06.03.02 ; Бюл. изобр. № 21, 2002 г.

\section{References}

1. Shamaev V. A., Nikulina N. S., Medvedev I. N. Modification of wood: monograph. Moscow: FLINTA : Nauka, 2013. 448 p. (in Russian).

2. Möttönen V., Bütün Y., Heräjärvi H. (et al.) (2015) Effect of combined compression and thermal modification on mechanical performance of aspen and birch wood. Pro Ligno. Vol. 11, No. 4, pp. 310-317.

3. Gubanova N. (2013) Modeling the process of wood impregnation with liquid. Bulletin of Moscow State Forest University - Forest Bulletin. № 3 (95), p. 134-138 (in Russian).

4. Cox P. E. Wood hardening procedures. Pat. USA WO2006121352A1, PCTNZ 2006/000105. 2006. 11 p.

5. Papadopoulos A. N., Mantanis G. I. (2012) Vapour Sorption Studies of Belmadur Wood. Advances in Forestry Letter (AFL). Vol. 1, Issue 1, pp. 1-6.

6. Poncsak S., Kocaefe D., Younsi R. (2011) Improvement of the heat treatment of jack pine (Pinus banksiana) using thermowood technology. Holz als Rohund Werkstoff. Vol. 69, № 2, pp. 281-286.

7. Tyuleneva E. M. (2008) Refinement of the rheological model of wood. Coniferous boreal zones, XXV, No. 1-2, pp. 179-183 (in Russian).

8. Shamaev V. A., Kunitskaya O. A., Grigoryev I. V. (et al.) (2018) Impregnation of wood with liquids under pressure. Systems. Methods. Technology. № 4 (40), pp. 152-156. DOI 10.18324/2077-5415-2018-4-152-156.

9. Durability of Modified Wood - Laboratory vs Field Performance. Westin Mats, Technical Research Institute of Sweden, Boras, Sweden, 2010, 142.

10. Official site of Accoya company. URL: https:/www.accoya.com/why-accoya/benefits/. 
11. Official site of Kebony company. URL: http://kebony.com/en/products/.

12. Pat. RF No. 2185958 Shamaev V. A. Method of making wooden sleepers / V. A. Shamaev, A. A. Tomin, A. I. Sidelnikov. Appl. 11.08.2001, publ. 06.03.02 Bul. fig. No. 21, 2002 (in Russian).

\section{Сведения об авторе}

Шакирова Оксана Ивановна - соискатель ученой степени, ведущий специалист информационноаналитического отдела ФГБОУ ВО «Воронежский государственный лесотехнический университет имени Г.Ф. Морозова», г. Воронеж, Российская Федерация; e-mail: oks.vrn36@yandex.ru.

\section{Information about the author}

Shakirova Oksana Ivanovna - PhD applicant, leading specialist of the information and analytical department, FSBEI HE "Voronezh State University of Forestry and Technologies named after G.F. Morozov", Voronezh, Russian Federation; e-mail: oks.vrn36@yandex.ru. 